\title{
Effect of Medicinal Plants on Free Radical Scavenging: Herb-Herb Interactions
}

\section{MOHAMMAD MOMEN HERAVI, SHAHLA DANESHMEHR* and ALI MORSALI}

Department of Chemistry, Mashhad Branch, Islamic Azad University, Mashhad, Iran.

*Corresponding author E-mail: shahladaneshmehr@yahoo.com

http://dx.doi.org/10.13005/ojc/310170

(Received: January 2, 2015; Accepted: February 14, 2015)

\begin{abstract}
This study was done to investigate the interaction effect of the mixture of each pair of traditional medicinal plants including: Sage (Salvia officinalis), Hawthorn (Crataegusoxyacantha), Walnut Leaf (Juglansregia L.), Red Cabbage (Brassica oleracea), and Yellow Sweet Clover (Melilotus officinalis) on the antioxidant activities and free radical scavenging by using DPPH (2, 2-diphenyl-1-picrylhydrazyl) assay at different temperatures. Results showed that free radical scavenging in the presence of Walnut Leaf mixed with four other plants and Hawthorn mixed with Sage and Red Cabbage increased with increasing temperature while, in the presence of other mixtures decreased with increasing temperature.
\end{abstract}

Key words: Herb, Free Radical, Medicinal Drug, Scavenging Activity.

\section{INTRODUCTION}

Herbs have been frequently used in many domains including medicine, nutrition, flavoring, beverages, dyeing, repellents, fragrances, cosmetics, smoking, and other industrial purposes ${ }^{1-}$ ${ }^{3}$. Beside herbal drugs, using synthetic drugs were also developed since the nineteenth century ${ }^{4}$. Researchers have been interested in finding natural antioxidants in order to be used in foods or medicinal materials instead of synthetic antioxidants due to many side effects ${ }^{5}$. Many medicinal plants include large amounts of antioxidants such as polyphenols, flavonoids, quercetin, etc ${ }^{6}$. So, research to determine antioxidative compounds is an important subject ${ }^{7}$. Compounds of medical plants are the active ones are not clear. However, polyphenols recently have been considered more because of some new findings regarding their biological activities ${ }^{8,9}$. The antioxidant properties of polyphenols, such as free radical scavenging and inhibition of lipid peroxidation, are the most important from pharmacological and therapeutic aspects ${ }^{10}$. The reason for choosing medicinal plants in this study is that they are efficient in the treatment of different cancerous lesions of the stomach, colon, rectum esophagus, liver, hypertention, oedema, and as 
detoxicant, diuretic, anti-inflammatory, anti-pyretic and anti-purulent agents ${ }^{11}$. Sage (Salvia officinalis), Hawthorn (Crataegusoxyacantha), Walnut Leaf (Juglansregia L.), Red Cabbage (Brassica oleracea), and Yellow Sweet Clover (Melilotusofficinalis) as medicinal plants and sources of natural antioxidants are effective in the treatment of free radical related disorders ${ }^{7,12}$. More research was done about herb-drug, food-drug, nutrient-drug and drug-drug interactions ${ }^{13-15}$. But because most people believe the use of mixture of medicinal plants have no side effects and antioxidant activities can be either constant or increasing. In this paper, the effect of herb-herb interaction on free radical scavenging at different temperatures and comparing them with previous studies has been investigated.

\section{MATERIALS AND METHODS}

\section{Chemical and reagent}

The reagent 2, 2-Diphenyl-1picrylhydrazyl (DPPH) was purchased from Sigma (St. Louis, USA). All the other reagents (Acetonitrile, Hydrochloric Acid and Ethanol) were obtained from Merck (Germany).

\section{Plant materials and preparation of extracts}

Fresh plants including: Sage (Salvia officinalis), Hawthorn (Crataegusoxyacantha), Walnut Leaf (Juglansregia L.), Red Cabbage (Brassica oleracea), and Yellow Sweet Clover (Melilotusofficinalis) were gathered from Azerbaijan mountains located at northwest of Iran. The collected samples were dried at ambient temperature and under sunlight for 5 days. Dried plants were milled using a standard sample mill (300 Waufn S2, Germany) and in turn extracted with two solvents: $\mathrm{HCl}(1.5 \mathrm{M})$ and ethanol (95\%) and $2 \mathrm{~g}$ of each samples were extracted by dissolving in $85 \mathrm{~mL}$ ethanol and $15 \mathrm{~mL} \mathrm{HCl}$. Flasks were kept in a shaking incubator (Boekel Jitterbug Microplate, Cole-Parmer, USA) at $1000 \mathrm{rpm}$ under $40^{\circ} \mathrm{C}$ for $1 \mathrm{~h}$. The extracts were subsequently concentrated at 40 ÚC for $15 \mathrm{~min}$. Finally, the infusions were filtered through Whatman filter paper twice, until a clear extract was acquired.

\section{Instrumentation}

Spectrophotometric data were obtained using
Perkin Elmer Lambda 25 UV-Vis spectrophotometer. Glass matched cuvettes $(1 \mathrm{~cm} \times 1 \mathrm{~cm} \times 4.5 \mathrm{~cm})$ were used for UV-Vis absorbance measurements. The temperature in the cell was controlled by using JULABO Heating Immersion Circulator.

\section{DPPH radical scavenging assay}

DPPH (2, 2-diphenyl-1-picrylhydrazyl) radical scavenging assay is mostly applied to rapidly examine the antioxidant capacity of plant extracts. Under experimental conditions, DPPH reagent shows a strong absorption band at $517 \mathrm{~nm}$. The solution of DPPH in acetonitrile $\left(6 \times 10^{-5} \mathrm{M}\right)$ was prepared daily, before UV-Vis measurements. $3 \mathrm{~mL}$ portions of this solution were mixed with freshly prepared alcoholic extracts with $1 \mu \mathrm{L}$ extract solution consists of $0.5 \mu \mathrm{l}$ of each extract (extract: ethanol, $1: 10 \mathrm{v} / \mathrm{v}$ ). Acetonitrile was used as a blank solution. The experiments were repeated in triplicate. The percentage of DPPH radical scavenging by the samples was calculated according to formula, \% Scavenging $=\left[\left\{A_{i}-A_{f}\right\} / A_{i}\right] \times 100$, where $A_{i}$ control is the absorbance of DPPH radical, $A_{f}$ sample is the absorbance of DPPH radical with extract after $30 \mathrm{~min}$.

\section{RESULTSAND DISCUSSION}

Results of free radical scavenging percentage in the presence of mixtures of each pair of ethanolic extracts including: Sage, Red Cabbage, Walnut Leaf, Yellow Sweet Clover and Hawthorn at temperatures ranging from $25^{\circ} \mathrm{C}$ to $40^{\circ} \mathrm{C}$ were provided in Table 1 . The results in Table 1 demonstrated that the highest free radical scavenging percentage was related to the ethanolic extract of Walnut Leaf \& Red Cabbage at all temperatures ranging and with increased temperature increased free radical scavenging percentage, while the lowest free radical scavenging percentage were related to Walnut Leaf \& Hawthorn at 25,28 and $31^{\circ} \mathrm{C}$ and Sage \& Yellow Sweet Clover at 34,37 and $40^{\circ} \mathrm{C}$. Comparing results of free radical scavenging percentage in the presence of ethanolic extracts of Sage, Red Cabbage, Walnut Leaf, Yellow Sweet Clover and Hawthorn one by one ${ }^{12}$ and mixtures of each pair of plants with same concentration at temperatures ranging from $25^{\circ} \mathrm{C}$ to $40^{\circ} \mathrm{C}$ indicated that free radical scavenging for mixtures of extracts reduced at all temperatures because of herb-herb interaction. 
Table 1: Effect of Temperature on the Free Radical Scavenging

\begin{tabular}{lcccccc}
\hline Temperature $\left({ }^{\circ} \mathbf{C}\right)$ / Plant & $\mathbf{2 5}$ & $\mathbf{2 8}$ & $\mathbf{3 1}$ & $\mathbf{3 4}$ & $\mathbf{3 7}$ & $\mathbf{4 0}$ \\
\hline Hawthorn \&Yellow Sweet Clover & 23.5 & 18.5 & 17 & 12 & 11 & 8 \\
Sage \&Yellow Sweet Clover & 12 & 10 & 9.5 & 3.5 & 3 & 1 \\
Sage \& Hawthorn & 12 & 17.5 & 19 & 21 & 21.5 & 22 \\
Red Cabbage \&Yellow Sweet Clover & 22 & 18 & 17 & 16.5 & 16 & 14 \\
Hawthorn \& Red Cabbage & 17 & 23.5 & 27 & 29 & 32.5 & 35 \\
Walnut Leaf \&Yellow Sweet Clover & 14 & 18 & 21 & 22 & 31 & 35 \\
Walnut Leaf \& Red Cabbage & 31 & 32 & 33 & 34 & 34.5 & 36 \\
Walnut Leaf \& Sage & 13 & 17 & 25 & 27 & 29 & 31 \\
Red Cabbage \& Sage & 29 & 25 & 23.5 & 23 & 22 & 19.5 \\
Walnut Leaf \& Hawthorn & 1.6 & 8 & 9 & 16 & 17 & 18 \\
\hline
\end{tabular}

\section{CONCLUSIONS}

The determination of free radical scavenging percentage in the presence of mixtures of each pair of ethanolic extracts at different temperatures was done. Results showed increasing or decreasing temperature had no same effect on the free radical scavenging percentage at the presence of medicinal plants. So that, free radical scavenging in the presence of Walnut Leaf mixed with four other plants and Hawthorn mixed with Sage and Red Cabbage increased with increasing temperature while, in the presence of other mixtures decreased with increasing temperature but at the presence of Walnut Leaf \& Red Cabbage, temperature had no significant effects. Finally this paper suggests that for preventing herb-herb interactions, medicinal plants as tea, food and fruit are used alone and it is better than mixtures of each pair.

\section{REFERENCES}

1. Bae, J.W.; Kim, D.H.; Lee, W.W.; Kim, H.Y.; Son, C.G. J. Ethnopharmacol.2015, 162, 1-6.

2. Duan, L.X.; Qi, X.; Chen, M.; Huang, L.Q., Application of Metabolomics in the Identification of Chinese Herbal Medicine. (Ed.), Plant Metabolomics. Springer, Netherlands.2015, pp. 227-244.

3. Durak, A.;Gawlik-Dziki, U.;Kowlska, I. Food Chem. 2015,166, 261-269.

4. Exarchou, V.;Nenadis, N.;Tsimidou, M.;Gerothanassis, I. P.;Troganis, A.;Boskou, D. J. Agr. Food Chem.2002,50(19), 52945299.

5. Velioglu, Y. S.;Mazza, G.;Gao, L.;Oomah, B. D. J. Agr. Food Chem.1998,46, 4113-4117.

6. Atanassova, M.;Georgieva, S.;Ivancheva, K. J. Chem. Tech. Metall.2011,46, 81-88.

7. Hamdy Roby, M.H.;Sarhana, M.A.;Selima, K.A.H.;Khalel, K.I. Ind. Crop Prod. 2013,43,
827-831.

8. Jaiswal, A.K.; Gupta, S.; Abu-Ghannam, N. Food Chem.2012,131, 63-72.

9. Turkmen, N.; Sari, F.;Velioglu, Y.S. Food Chem.2006,99: 835-841.

10. Ali, B.H.; Blunden, G.;Tanira, M.O.;Nemmar, A. Food Chem. Toxicol.2008,46, 409-420.

11. Heo, B.G.; Park, Y.J.; Park, Y.S.;Bae, J.H.; Cho, J.Y.; Park, K.;Jastrzebskif, Z.; Gorinsteing, S.Ind. Crop Prod.2014, 56, 9-16.

12. Daneshmehr, S.;Momen-Heravi, M.;Morsali, A. Int. J. Curr. Life Sci. 2014,4(9), 7615-7618.

13. Fasinu, P.S.;Bouic, P.J.;Rosenkranz, B. Front. Pharm.2012,3, 69.

14. Tarirai, C.;Viljoen, A.M.;Hamman, J. H. Expert Opin. Drug Metab.Toxicol.2010,6, 15151538.

15. Williamson, E.M. Expert Opin. Drug Safe.2005,4: 355-378. 